\title{
Metastatic Eccrine Porocarcinoma: A Rare Case of Successful Treatment
}

\author{
Hiren Mandaliya Ina Nordman \\ Medical Oncology, Calvary Mater Newcastle, Waratah, N.S.W., Australia
}

\section{Keywords}

Eccrine porocarcinoma $\cdot$ Malignant eccrine poroma

\begin{abstract}
The successful treatment of the rare malignancy eccrine porocarcinoma (EP) is extremely challenging, often not rewarding and when associated with metastatic disease, therapy results are disappointing. We present a unique case of treatment response of metastatic EP, with a significant disease-free interval. The patient has remained in clinical and radiological remission for 36 months since diagnosis of metastatic disease.

(C) 2016 The Author(s)

Published by S. Karger AG, Basel

\section{Case}

A 66-year-old Caucasian female first treated for right forearm cutaneous primary eccrine porocarcinoma (EP) with curative surgery 14 years ago. Her other significant history included basal cell carcinoma requiring surgical resection and radiation therapy; superficial melanoma managed with surgical excision. Four years after the excision of her cutaneous EP, she had a biopsy-proven ipsilateral axillary recurrence of her EP. She was managed with a radical extended lymphadenectomy and post-operative radiotherapy (60 Gy/30 fractions) to right axilla. Her progress was complicated by lymphedema of the right upper limb. She continued on a regular surveillance and remained well (apart from lymphedema) for 6 years.
\end{abstract}




\section{Case Reports in Oncology}

Six years following the treatment for local recurrence, she developed metastatic disease to the mediastinal lymph nodes and ipsilateral arm associated with progressive shortness of breath, cough, lethargy and hypercalcemia. Bronchoscopy-guided mediastinal lymph node biopsy (EBUS) confirmed recurrence of EP and excluded other malignancies including melanoma and basal cell carcinoma. The burden of her disease was measured on positron emission tomography (PET) scan.

After an extensive literature review, she was treated with concurrent chemoradiation [cisplatin and docetaxel combination chemotherapy along with radiation therapy to mediastinum (50 Gy/25 fractions)] for 6 weeks.

After treatment, she underwent a PET scan to assess her response. PET scan demonstrated complete response with chemoradiation therapy without any evidence of disease at mediastinum, right arm or elsewhere. Her symptoms resolved and her calcium normalised.

Since then she has been on a regular surveillance. Her most recent imaging confirms ongoing response with a complete response on PET/CT. She remains clinically well and her lymphedema is stable.

\section{Discussion}

EP (malignant eccrine poroma) is one of the subtypes of a rare tumour of eccrine sweat glands characterised with primary adenocarcinoma. The tumour originates from the intraepidermal portion of the eccrine duct or acrosyringium. It represents only $0.01 \%$ of all cutaneous epithelial neoplasms [1].

Clinically it is difficult to differentiate from other cutaneous lesions such as seborrheic keratosis, pyogenic granuloma, amelanotic melanoma, squamous cell carcinoma, basal cell carcinoma, verruca vulgaris and metastatic adenocarcinoma; hence, histopathology is the most useful to confirm the diagnosis of EP $[2,3]$. High mitosis $(>14 / 10 \mathrm{HPFs})$, lymphovascular invasion and depth of tumour more than $7 \mathrm{~mm}$ are indicators of poor prognosis [4].

EP is more common among older individuals and predominantly affects the lower extremities and the head. About 20\% of EP will recur and around 20\% metastasise to regional lymph nodes. Rarely, it can metastasise to viscera such as lungs, pleura, brain, mediastinum, retroperitoneum, breast, etc. As based on a literature review, this cutaneous malignancy has a high mortality rate with approximately $67 \%$ mortality noted in patients with lymph node metastasis [2], with expected survival of those who metastasise reported between 5 and 24 months [5].

Treatment modalities include Moh's micrographic surgery, chemotherapy and radiation therapy [6]. Adjuvant radiation therapy showed benefits in the histopathologically poorprognosis group [7]. There has been little evidence of a specific chemotherapy-based regimen in metastatic EP due to the rarity of this cancer and proven relatively resistant to many cytotoxic agents [8]; hence, optimal treatment has not been standardised yet. Varieties of chemotherapeutic agents used in combination therapy are, for example, doxorubicin, mitomycin, vincristine and 5-fluorouracil; anthracycline, cyclophosphamide, vincristine and bleomycin; isotretinoin and interferon-alpha; carboplatin and paclitaxel; cisplatin and docetaxel; paclitaxel and interferon-alpha [9], etc. Each has variable success inform of response, durability and toxicities.

Metastatic EP has been refractory to multiple treatment regimens including radiation and chemotherapy. Because of this and the tendency to develop local recurrences, a surgical excision of the primary tumour is the treatment of choice and curative in $70-80 \%$ of cases 
[10]. Although radiotherapy has not been significantly beneficial in metastatic EP as described in the literature, our case has demonstrated that a significant disease-free interval can be achieved after concurrent chemoradiation therapy.

\section{Conclusion}

Our patient had an excellent response to treatment with a very prolonged complete response achieved; which is significantly longer than reported in different series (noted between 3 and 12 months). Hence, we conclude that, in patients with disease amenable to dual modality therapy, chemoradiation should strongly be considered.

\section{Statement of Ethics}

The authors have no ethical conflicts to disclose.

\section{Disclosure Statement}

The authors declare no conflict of interest.

\section{References}

1 Mehregan AH, Hashimoto K, Rahbari H: Eccrine adenocarcinoma. A clinicopathologic study of 35 cases. Arch Dermatol 1983;119:104-114.

2 Huet P, Dandurand M, Pignodel C, Guillot B: Metastasizing eccrine porocarcinoma: report of a case and review of the literature. J Am Acad Dermatol 1996;35:860-864.

3 Whitt P, Whelchel J, Ruff T: Eccrine porocarcinoma. Ear Nose Throat J 1996;75:536-538.

4 Robson A, Greene J, Ansari N, et al: Eccrine porocarcinoma (malignant eccrine poroma): a clinicopathologic study of 69 cases. Am J Surg Pathol 2001;25:710-720.

-5 Grimme H, Petres A, Bergen E, et al: Metastasizing porocarcinoma of the head with lethal outcome. Dermatology 1999;198:298-300.

6 De Iuliis F, Amoroso L, Taglieri L, et al: Chemotherapy of rare skin adnexal tumors: a review of literature. Anticancer Res 2014;34:5263-5268.

7 Tlemcani K, Levine D, Smith RV, et al: Metastatic apocrine carcinoma of the scalp: prolonged response to systemic chemotherapy. J Clin Oncol 2010;28:e412-e414.

-8 Plunkett TA, Hanby AM, Miles DW, Rubens RD: Metastatic eccrine porocarcinoma: response to docetaxel (Taxotere) chemotherapy. Ann Oncol 2001;12:411-414.

-9 Gutermuth J, Audring H, Voit C, et al: Antitumour activity of paclitaxel and interferon-alpha in a case of metastatic eccrine porocarcinoma. J Eur Acad Dermatol Venereol 2004;18:477-479.

10 Goel R, Contos MJ, Wallace ML: Widespread metastatic eccrine porocarcinoma. J Am Acad Dermatol 2003;49:S252-S254. 